\title{
Community structure in pelagic marine mammals at large spatial scales
}

\author{
R. S. Schick 1,* , P. N. Halpin ${ }^{1,2}$, A. J. Read ${ }^{2,1}$, D. L. Urban ${ }^{1}$, B. D. Best ${ }^{1,2}$, \\ C. P. Good ${ }^{1,2}$, J. J. Roberts ${ }^{1}$, E. A. LaBrecque ${ }^{1,2}$, C. Dunn ${ }^{3}$, L. P. Garrison ${ }^{4}$, \\ K. D. Hyrenbach ${ }^{1,2}$, W. A. McLellan ${ }^{5}$, D. A. Pabst' ${ }^{5}$, D. L. Palka ${ }^{6}$, P. Stevick ${ }^{7}$ \\ ${ }^{1}$ Nicholas School of the Environment, Duke University, Durham, North Carolina 27708-0328, USA \\ ${ }^{2}$ Duke University Marine Laboratory, 135 Duke Marine Lab Road, Beaufort, North Carolina 28516-9721, USA \\ ${ }^{3}$ Bahamas Marine Mammal Research Organisation, PO Box AB-20714, Marsh Harbour, Abaco, Bahamas \\ ${ }^{4}$ NOAA, Southeast Fisheries Science Center, 75 Virginia Beach Dr., Miami, Florida 33027, USA \\ ${ }^{5}$ Department of Biology and Marine Biology, University of North Carolina Wilmington, 601 S. College Road, Dobo Hall 102, \\ Wilmington, North Carolina 28403-5915, USA \\ ${ }^{6}$ NOAA, Northeast Fisheries Science Center, 166 Water Street, Woods Hole, Massachusetts 02543-1026, USA \\ ${ }^{7}$ Bioscience Research Institute, University of Southern Maine, 96 Falmouth St., 176 Science Building, Portland, \\ Maine 04104-9300, USA
}

\begin{abstract}
The understanding of a species' niche is fundamental to the concept of ecology, yet relatively little work has been done on niches in pelagic marine mammal communities. Data collection on the distribution and abundance of marine mammals is costly, time consuming and complicated by logistical difficulties. Here we take advantage of a data archive comprising many different datasets on the distribution and abundance of cetaceans from Nova Scotia through the Gulf of Mexico in an effort to uncover community structure at large spatial scales $(1000 \mathrm{~s} \mathrm{of} \mathrm{km})$. We constructed a multivariate ordination of the species data, tested for group structure that might exist within the ordination space, and determined how these groups might differ in environmental space. We examined 3 biogeographic regions: the oceanic waters north and south of Cape Hatteras, NC, and the Gulf of Mexico. North of Hatteras, we found 2 main groups split along a temperature and chlorophyll gradient, with most piscivores being found in cooler, more productive waters of the continental shelf, and most teuthivores being found farther offshore in warmer, less productive waters at the shelf break (200 m isobath). South of Hatteras, we found 3 groups, with the largest group being in warmer, lower chlorophyll waters that are closest to shore. In the Gulf of Mexico, we found 7 groups arrayed along a bottom depth gradient. We also tested the effect of taxonomically lumping different beaked whale species on ordination results. Results showed that when beaked whales were identified to the species level, they clustered out into distinct niches that are separate from those of other Odontocete groups. These results add to an increasing understanding of wildlife habitat associations and niche partitionings in the community structure of pelagic species, and provide important baseline information for future population monitoring efforts.
\end{abstract}

KEY WORDS: Cetaceans · Group contrast Mantel test · Nonmetric dimensional scaling $\cdot$ Multivariate ordination $\cdot$ Northwest Atlantic Ocean

Resale or republication not permitted without written consent of the publisher

\section{INTRODUCTION}

To uncover community structure and the environmental variables that produce such structure, community ecologists have long used multivariate ordinations to investigate how species associate and separate out into distinct communities (Austin 1985). Cluster analy- sis is typically used to form groups in multivariate space, and environmental data are then used to examine what environmental features are correlated with individual groups (Clarke \& Ainsworth 1993). An understanding of the groups and their position in environmental space has led to fundamental insights about what biotic and abiotic forces shape the distribution of 
species and communities. Many of these insights have come from terrestrial systems or nearshore marine systems (Austin 1985). In contrast, pelagic communities are hard to understand because they are comprised of mobile animals. Here we applied standard multivariate ordination techniques to a large dataset on the distribution and abundance of marine mammals in order to understand community structure and environmental relationships therein. We determined community structure in cetacean communities in 3 biogeographic zones in the Northwest Atlantic Ocean, and quantified the environmental relationships among species groups in these communities. Lastly, for management purposes, we examined how identifying sightings at sea to different taxonomic levels affects the structure of the pelagic communities.

Although some of the foundational literature in community ecology comes from the marine realm (Connell 1961, Paine 1966), much of this work has been focused on nearshore applications (e.g. Field et al. 1982, Clarke 1993, De'ath \& Fabricious 2000, Newman et al. 2006). Relatively little research has been done on the community structure of pelagic marine organisms, most likely due to the difficulty of gathering such data (Venrick 1990). Despite these difficulties, research in pelagic systems has shown clear gradients and structure in the following pelagic communities: marine phytoplankton (Venrick 1982, 1990); marine zooplankton (McGowan \& Walker 1979, 1985); marine birds (Ballance et al. 1997, Woehler et al. 2003, Hyrenbach et al. 2007); and marine mammals (Fiedler \& Reilly 1994, Reilly \& Fiedler 1994, Baumgartner et al. 2001, Hamazaki 2002, Palacios 2003).

Furthermore, 2 additional factors complicate community structure analysis in pelagic organisms: (1) their behavior, notably their movement, offers unique challenges; and (2) their dynamic environment moves and changes temporally as well. For large marine mammals, these hypervolumes (Hutchinson 1957) are often spatially and temporally distinct, and are often separated by dominant oceanographic features. For example, many large whales spend significant and discrete portions of the year being engaged in the following activities: breeding/calving, migrating, and feeding. Niche requirements for each of these phases are typically quite different. In some cases (e.g. humpback whales), these behaviors are spatially distinct, while in others (e.g. right whales in the Gulf of Maine; Kraus \& Rolland 2007), breeding and feeding can overlap in space and time. In such cases, observations of individual whales without additional knowledge of what the organism is actually doing (feeding, breeding, etc.) may complicate our understanding of its position in a community. The observed distribution of these species may be affected by the variables that individual species respond to, which exist at different scales and hierarchies. What a feeding right whale might respond to oceanographically may be different from what a migrating right whale might respond to.

Uncovering structure in cetacean communities will give scientists a baseline reference of the macro-scale community ecology of different biogeographic systems. In addition, understanding the biotic links between species will help in the implementation of ecosystem based management. Finally, information about community structure will provide managers with information on the gaps in existing data collection efforts at multiple trophic levels. For example in the Gulf of Maine, there are relatively fewer sightings of marine mammals in the non-summer seasons owing to the difficulty of data collection in bad weather. Understanding where these gaps are in space and time can help managers decide how to program specific data collection efforts to enhance our understanding of community dynamics throughout all seasons. By using ordination techniques, we can refine our knowledge of species position in different communities, and graphically see the effect of gaps in data. Here we used nonmetric multidimensional scaling (NMDS) to uncover the structure of pelagic marine mammal communities. We present static ordination results, uncovered groups in the data, and correlated group/community position with environmental features.

\section{MATERIALS AND METHODS}

General approach. We used methods described by Field et al. (1982), Clarke (1993), and Urban et al. (2002) to perform a multivariate analysis of the species data. After assembling the database(s), we performed NMDS analysis of the data, which we plotted on top of interpolated and smoothed environmental surfaces. Following this ordination, we used group contrast Mantel tests and hierarchical clustering techniques to find optimal groupings in the species assemblages. Finally, we used Mantel tests to assess how these groups differed in environmental space.

In preparing the data for this analysis, we have necessarily made several simplifying assumptions concerning the following aspects of the data: (1) the distribution of survey effort and the sightability of different species as a function of platform type, i.e. vessel or plane; (2) the changes in distribution patterns over time; (3) the size of the sampling sites; and (4) the environmental variables that may be influencing species distribution and community associations. Of these assumptions, the most influential is perhaps the first 
one because animals are differentially sighted from different survey platforms. To test the effect of lumping sightings by platform type, we re-analyzed the North of Hatteras $(\mathrm{NOH})$ data collected from each of the 2 different survey platforms. While the plane data were biased inshore, the groups that emerged from the data were similar in both instances (see Supplement 1 available at www.int-res.com/articles/suppl/m434p165_ supp.pdf). In addition, for the South of Hatteras ( $\mathrm{SOH}$ ) and the Gulf of Mexico (GOM), essentially all of the effort was vessel-based. These results gave us confidence in the approach we took. (See Supplement 1 for a discussion of all these assumptions.)

Building on ideas put forth by Stommel (1963), Steele (1991) outlined the precise scale specific relationships in marine communities. Although we have chosen specific temporal and spatial scales for this analysis, it is important to frame the analysis within a broader context. Because we have chosen a fixed spatial and temporal extent, we are effectively ignoring the hierarchical nature of some species-environment relationships known to exist. For example, right whales inhabit much of the habitat included here, but in very different spatial patterns. At times they inhabit coastal waters as they migrate long distances; at other times they are in the Gulf of Maine feeding and breeding. Within the Gulf of Maine, i.e. at a different level of the hierarchy, they occupy specific feeding and breeding areas, e.g. the Bay of Fundy. Within the Bay of Fundy, they occupy even more specific areas at specific times, i.e. following copepod concentration at depth at certain times in the tidal cycle (Baumgartner et al. 2003). Because we have chosen a broader spatial and temporal domain, we are not examining these changing behavioral patterns at the species level, and the effect of these changes at the community level.

Data collection and preparation. Sightings data for individual cetacean species were taken from the Ocean Biogeographic Information System - Spatial Ecological Analysis of Megavertebrate Populations (OBIS-SEAMAP) project (Halpin et al. 2006, Halpin et al. 2009; all data used here are available online at http://seamap.env.duke.edu/species). OBISSEAMAP houses data observed from a variety of different platforms: ships of opportunity, and devoted vessel-based and plane-based cetacean surveys (Halpin et al. 2006, 2009). Regardless of the platform type for each sighting, we extracted spatially and temporally specific environmental information (see Best et al. 2007 for specifics of the data and the workflow). We used R (R Development Core Team 2010) to co-locate the position of the sighting with each of 7 environmental layers comprised of the following: (1) sea surface temperature (SST); (2) chloro- phyll a (chl a) concentration; (3) bottom depth; (4) distance to continental shelf (defined by the $200 \mathrm{~m}$ isobath); (5) distance to shore; and 2 climatologies representing (6) probability of an SST front, and (7) depth of the mixed layer (MLD). All environmental layers and sightings data were projected into the Lambert Equal-Area projection to preserve areal consistency (Best et al. 2007). The SST and chlorophyll data from the SeaWiFS (Sea-viewing Wide Field-of-view Sensor) satellite were taken from the Physical Oceanography Distributed Active Archive Center (PO.DAAC; http://podaac.jpl.nasa.gov/) (Best et al. 2007). The SST fronts probability climatology was taken from the data archive created as part of the Marine Geospatial Ecology Toolbox (Roberts et al. 2010). The MLD data were sampled from a $1^{\circ}$ latitude resolution monthly climatology (we used July), available from the University of Hawaii (School of Ocean and Earth Science and Technology, SOEST; http:// apdrc.soest.hawaii.edu/las/v6/index).

We assembled a sites by species matrix by first creating a spatial layer of $50 \mathrm{~km}$ wide hexagons (Figs. 1 \& 2). We chose this size based on exploratory analysis of the data, and because it represents a compromise between biology and technical feasibility (see Supplement 1 for further discussion of the hexagons). We then intersected these hexagons with the sightings data to create a presence-absence data matrix comprised of site ID (rows) and species present on that site (columns). We limited our ordination to the summer season, which we defined as the months of June through August. This temporal extent was based on the preponderance of survey effort and sightings data. We created a climatology of the species composition during the summer months over all years (1991 to 2005). While we acknowledge the potential confounding influence of time (e.g. species trends and changes in distribution over the 14 yr dataset), the data are limited, especially in non-summer months; hence, we were unable to examine the temporal (within and across years) progression of species in ordination space. Therefore, this analysis provides a summertime climatological community-level analysis for the period spanning from 1991 to 2005.

We divided the geographic area into 3 biogeographic regions corresponding to the Gulf of Mexico (GOM), South of Cape Hatteras (SOH), and North of Cape Hatteras, (NOH) (Figs. $1 \& 2$ ). These breaks were chosen based on an understanding of the physical biogeography of the area (Ekman 1953, Angel 1979, MacLeod 2000, Spalding et al. 2007). Lastly, for NOH we prepared data frames both with and without rare species, which we defined as species seen on $<5 \%$ of the sites (see Supplement 2 available at www. int-res.com/articles/suppl/m434p165_supp.pdf for a 


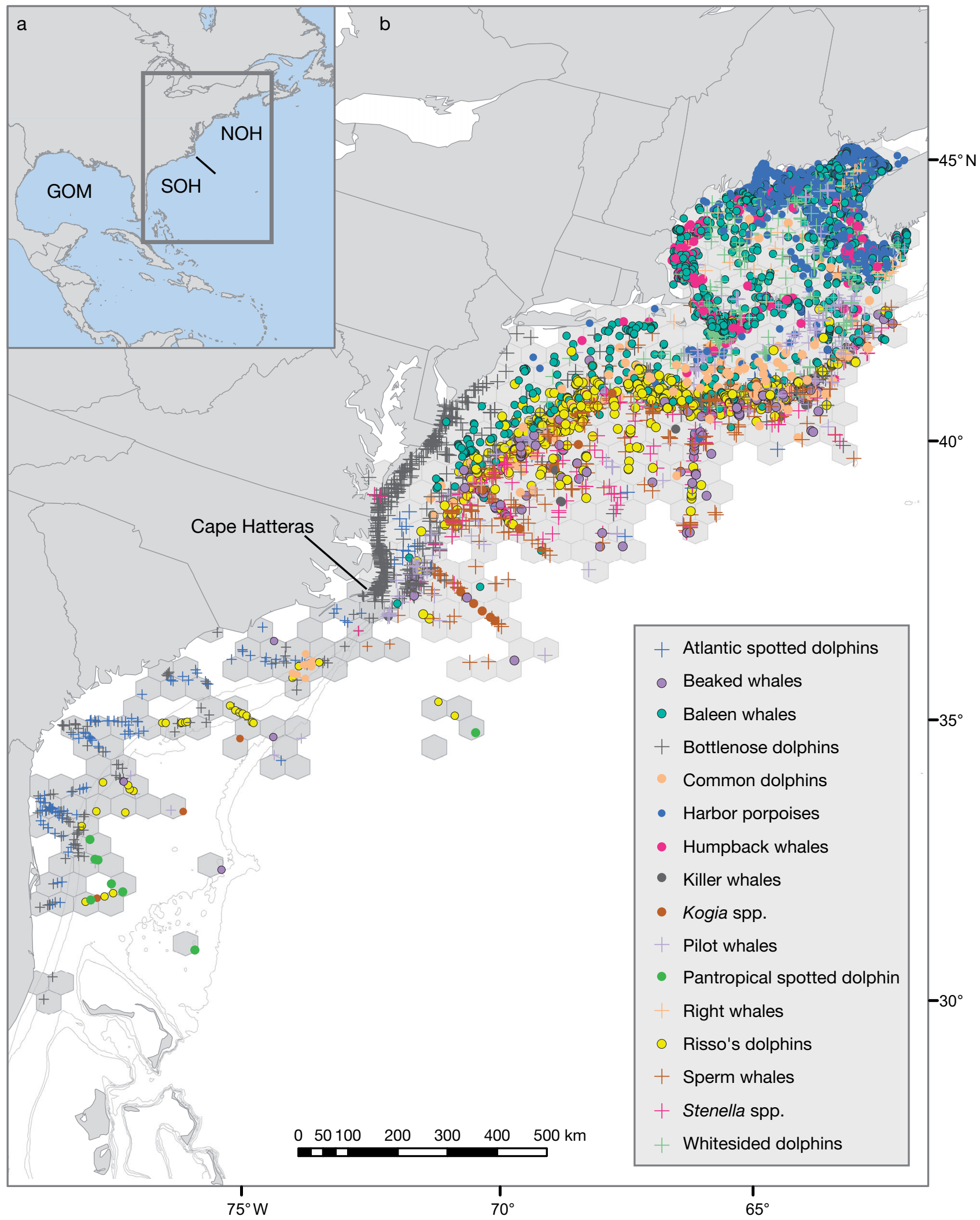

Fig. 1. The regions North of Hatteras (NOH) and South of Hatteras (SOH). (a) Overview. (b) Sampling hexagons (NOH: light grey; SOH: dark grey). Sightings are depicted at the taxonomic guild level with different colors and symbols. Depth contours (200, 500, $1000,2000 \mathrm{~m}$ ) in light grey. GOM: Gulf of Mexico 


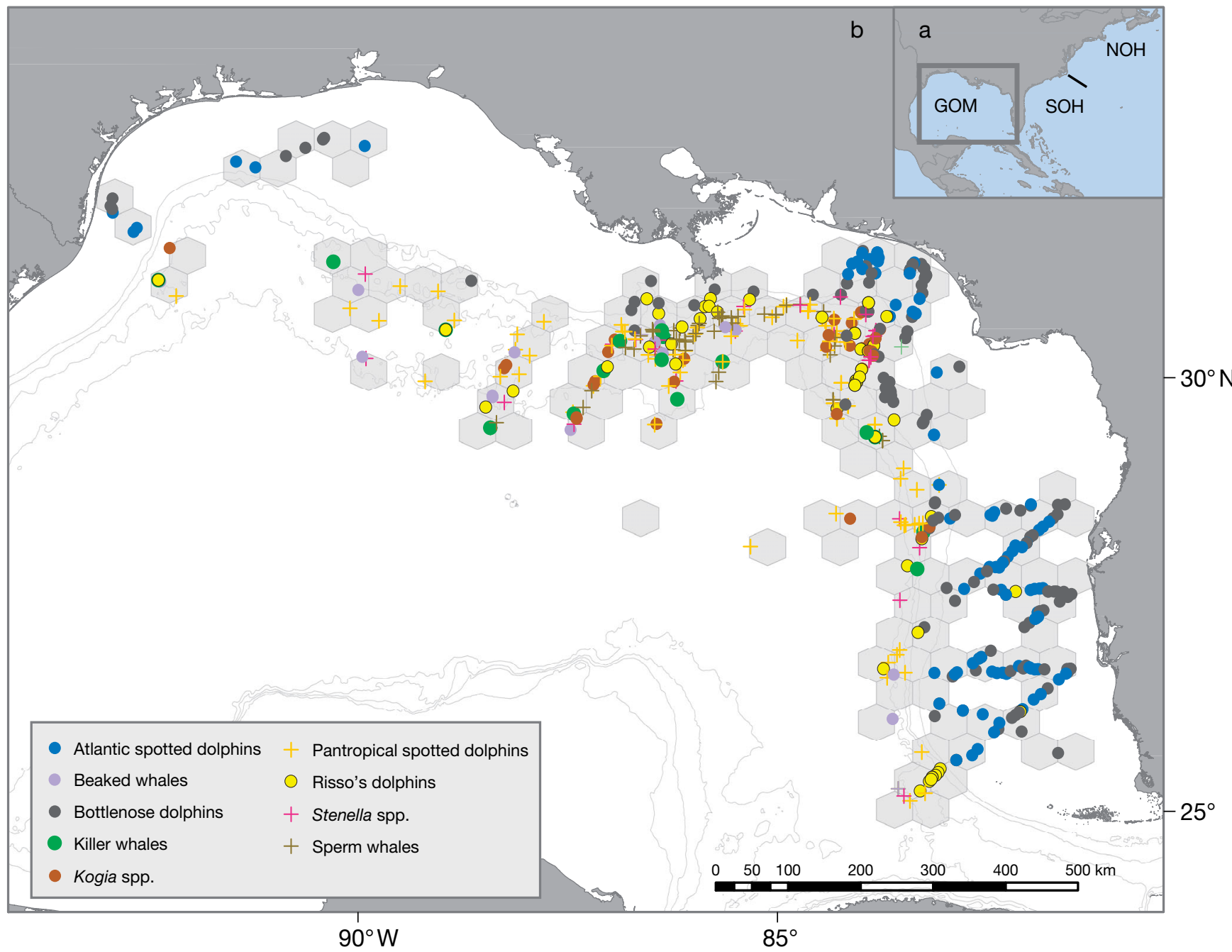

Fig. 2. The Gulf of Mexico (GOM). (a) Overview. (b) Sampling hexagons in light grey. Sightings are depicted at the taxonomic guild level with different colors and symbols. Depth contours $(200,500,1000,2000 \mathrm{~m})$ in light grey

full tabular summary of the species included in each analysis). For GOM and $\mathrm{SOH}$, the ordination converged only when the rare species were removed (see next section for details).

Ordination methods. We used the vegan package (Oksanen et al. 2010) in R to perform a species by sites analysis using NMDS. We used the Jaccard dissimilarity metric on the sites by species (presenceabsence) data frame. The Jaccard index is a well known metric for species presence-absence data, and defines similarity as $S=a /(a+b+c)$ (Legendre \& Legendre 1998), where $S$ represents similarity between 2 sites, a represents the number of times the sites are coded similarly (i.e. presence-presence), and $b$ and $c$ represent the number of times the sites are coded differently (i.e. presence-absence, or absence-presence). We used presence-absence data because (as part of data sharing agreements) we lacked full survey information for all the datasets, which precluded us from using abundance data. Specifically, we had the effort tracklines, but had no information on angle, bearing, etc. to individual sightings. While this approach (i.e. standardizing from abundance to presence) removes data from the analysis, it is conservative.

With the data assembled, we then ran several exploratory NMDS analyses to assess the dimensionality of the final solution. In each region, we settled on a $3 \mathrm{D}$ solution. For the $\mathrm{NOH}$ region, we ran two 3D NMDS ordinations: one for all species and one for the common species, i.e. rare species were removed, where rarity was defined as above. For both $\mathrm{SOH}$ and GOM, we ran a single 3D NMDS ordination for common species only, because including rare species in these areas caused the NMDS to fail. (See Supplement 2 for summary tables of each of the regions). 
In plotting the ordination results, we used the ordisurf function in the vegan package (Oksanen et al. 2010). This function fits an environmental surface using thin plate splines in a generalized additive model (GAM), and then uses results from the GAM to predict and plot the surface on a regularized grid (Oksanen et al. 2010). We used the following settings in the function: for the GAM we used 5 knots, and assumed a Gaussian family (Oksanen et al. 2010). The input data to the function were the environmental data noted above. The GAM equation is: $y=s\left(x_{1}\right)+s\left(x_{2}\right)$ where $y$ is the environmental variable, $s$ represents a thin plate spline, and $x_{1}$ and $x_{2}$ represent the first and second dimensions of the ordination results, respectively. The inclusion of the environmental variables does not influence the results but merely provides a visual reference to the types of environments each species or group of species is located in. We fit the 7 environmental variables to the ordination data using the envfit function in vegan, and plotted the 4 variables that provided the highest explanatory power ( $\mathrm{r}^{2}$ values not shown).

Classification. One of our primary analytical goals was to determine if natural groups existed in the species data. To find these groups, we iteratively conducted a group contrast Mantel test (Urban et al. 2002) between the species distance in the sites by species matrix and the group distance generated by hierarchical agglomerative clustering. The correlation pattern between these 2 distances helps uncover the optimal number of groups in the species data. To perform this iterative analysis, we implemented the following steps within a loop. First, we calculated a distance matrix of the species presence-absence data using the same Jaccard index as described above. We then ran hierarchical agglomerative clustering with group average linkages on this distance matrix where the output tree had a set number of groups. The output from this clustering is a vector denoting which species belong to which groups. We then used this clustering output to create a group contrast distance matrix using Euclidean distance. At each step in the loop, the number of groups in the clustering would change, i.e. at step 1 we would test species distance versus group distance for 2 groups; at step 2 we would test species distance versus group distance for 3 groups, etc. We iterated up from having all species in 2 groups to having as many groups as there were species.

Then, we ran a Mantel test between the species distance matrix and the group contrast matrix, and recorded the Mantel R coefficient. This test determines whether the distance between species in ordination space corresponds to the distance between groups, thereby highlighting the among- to within-group contrast. In theory, there is an optimal number of groups that maximizes the correlation between these dis- tances (Urban et al. 2002). To estimate this maximum correlation, we iterated over all possible numbers of groups, i.e. from 2 groups up to the number of species seen in the region, recording the Mantel $\mathrm{R}$ at each point. (Although we did not use the $\mathrm{p}$-values, the Mantel $R$ values were generated with $n=10000$ randomizations.) Plotting the Mantel $\mathrm{R}$ against the number of groups yields the optimal number of groups present in the species data (Fig. 3). We used this optimal number of groups in hierarchical clustering to create the final group membership vector.

Environmental differences. We used partial Mantel tests to examine group membership as predicted by the environmental variables while controlling for spatial autocorrelation (Urban et al. 2002). Tests of these forms help answer questions like 'Are species that are in the same groups also found in similar environments?' Similar to the use of the ordisurf function above, this test of the groups and environment does not influence the ordination results. The ordinations were performed solely on the species presenceabsence data, and these 2 procedures (ordisurf and Mantel tests) were used to help explain observed differences in the ordination.

Classifying observations at different taxonomic levels. Several of the species sighted throughout the 3 regions are cryptic and are difficult to identify to the species level, e.g. beaked whales (MacLeod 2000, Macleod \& Mitchell 2006, Macleod et al. 2006). To increase statistical power, researchers have lumped

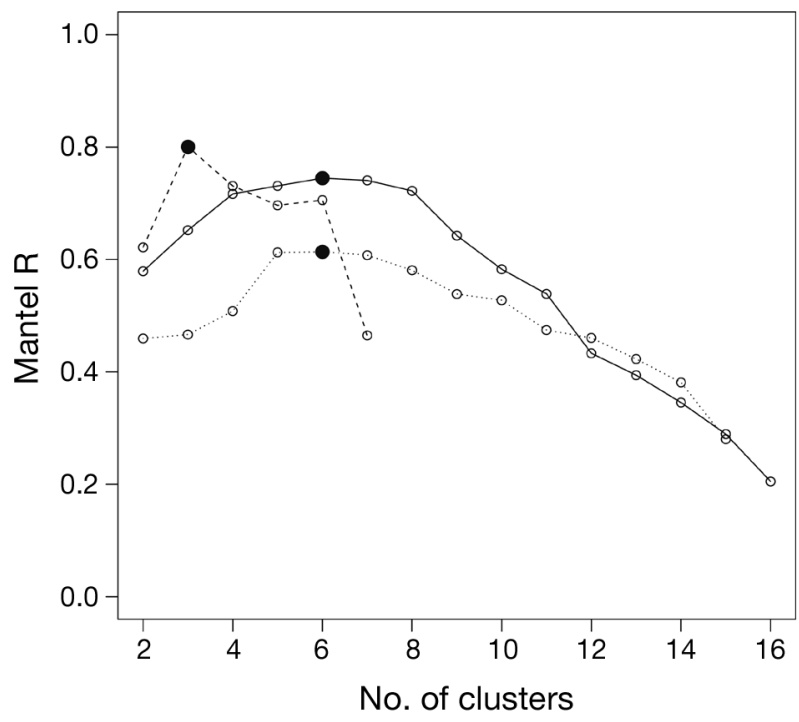

Fig. 3. Results from iterative group contrast Mantel tests between distances in species space and group space in the 3 regions (see 'Materials and methods-Classification' for details). Solid line: North of Hatteras, dashed line: South of Hatteras, dotted line: Gulf of Mexico, •: optimal number of groups in each region 
beaked whales of different species into one group (Waring et al. 2001). We tested the effects of classifying sightings at different taxonomic levels by running the $\mathrm{NOH}$ ordination twice: once with the sightings at the species level and again with the sightings lumped into coarser taxonomic categories.

\section{RESULTS}

\section{Overview}

We had a sufficient number of observations to reach convergence for both the complete species and com- mon species ordination only in the $\mathrm{NOH}$ region (Fig. 4). While we are often interested in the rarest species from a management perspective, they tended to dominate the results when included. The resulting structure often depicted these rare species as isolated from other species in ordination space, which made the more common species appear relatively clumped together, even when there was patterning therein (results not shown). In the $\mathrm{SOH}$ region, there were fewer species seen, and they were naturally spaced in the ordination (Fig. 5). In the GOM region, the common species were relatively evenly spaced, with 2 notable outliers - killer whales and Atlantic spotted dolphins (Fig. 6).
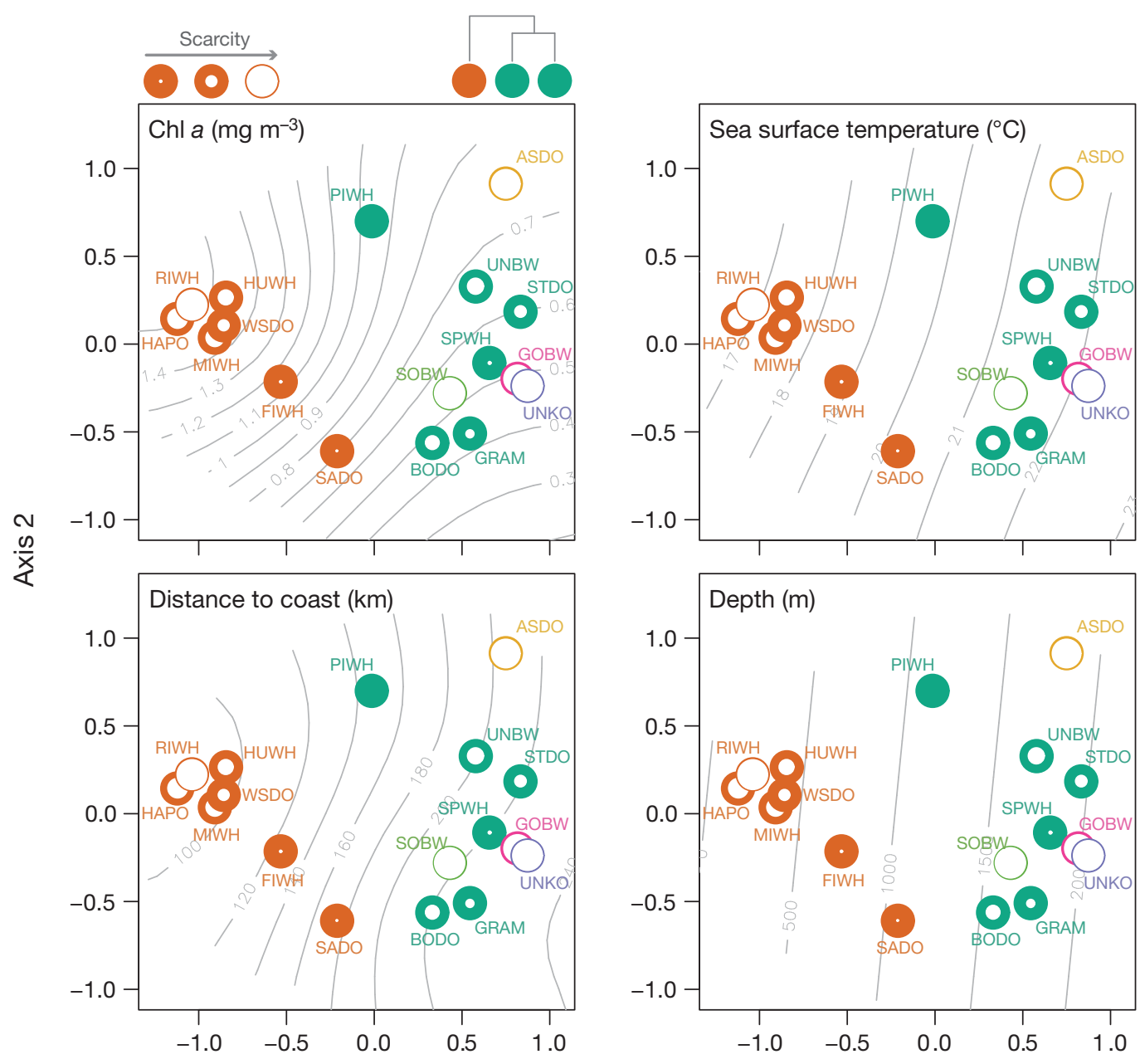

Axis 1

Fig. 4. Plot of NOH (North of Hatteras) species in ordination space (1st 2 axes) overlaid on a fitted environmental surface (grey contour lines). Species location is marked with 2 circles (see key upper left): (1) the size of the white inner circle corresponds to rarity level, i.e. a fully colored outer circle indicates abundance, while circles with a thin colored outline indicate rarity; (2) color corresponds to grouping from group contrast Mantel tests. Species are labeled as follows: ASDO: Atlantic spotted dolphin; BODO: bottlenose dolphin; FIWH: fin whale; GOBW: Cuvier's (goose-) beaked whale; GRAM: Risso's dolphin; HAPO: harbor porpoise; HUWH: humpback whale; MIWH: minke whale; PIWH: pilot whale; RIWH: right whale; SADO: common (saddleback) dolphin; SOBW: Sowerby's (North Sea) beaked whale; SPWH: sperm whale; STDO: striped dolphin; UNBW: unidentified beaked whale; UNKO: pygmy or dwarf sperm whale; WSDO: Atlantic white-sided dolphin 


\section{North of Hatteras}

Of the 3 regions, NOH contained the most data (31 species seen on 170 unique sampling hexagons). The species separated along Axis 1, with most of the squid eating species (Kenney \& Winn 1986) being to the right (positive along Axis 1), and most of the fish or plankton eating species (Kenney \& Winn 1986) being to the left (negative along Axis 1) (Fig. 4). Cluster analysis delineated 6 groups: 2 large ones, and 4 small ones (Fig. 4). The first large group was comprised of common dolphins (also called saddleback dolphins), Atlantic white-sided dolphins, harbor porpoises, minke whales, fin whales, humpback whales, and Northern right whales; this group is located closer to shore (Fig. 4). The species in the second large oceanic group were all Odontocetes: bottlenose dolphins, Risso's dolphins, sperm whales, striped dolphins, pilot whales, and unidentified beaked whales. The remaining 4 groups were each comprised of a single species: (1) Cuvier's beaked whales; (2) Sowerby's beaked whales; (3) Kogia spp.; and (4) Atlantic spotted dolphins (Fig. 4). The inshore, or neritic, species were in waters with the highest chl a concentration (Fig. 4), and were fairly clumped. These species were in the coolest waters, and were closest to shore (Fig. 4). Although the grouping into neritic and oceanic species was apparent, subtleties existed in the chlorophyll response. For example, although the oceanic group was seen in warmer waters (Fig. 4), there was a distinct gradient in the response to chlorophyll. This gradient went from those species in the group that were seen in the least productive waters (bottlenose and Risso's dolphins), through striped dolphins and sperm whales, to those seen in relatively more productive waters (beaked whales and pilot whales) (Fig. 4). With respect to chlorophyll and sea surface temperature, common dolphins, pilot whales and fin whales were seen approxi-
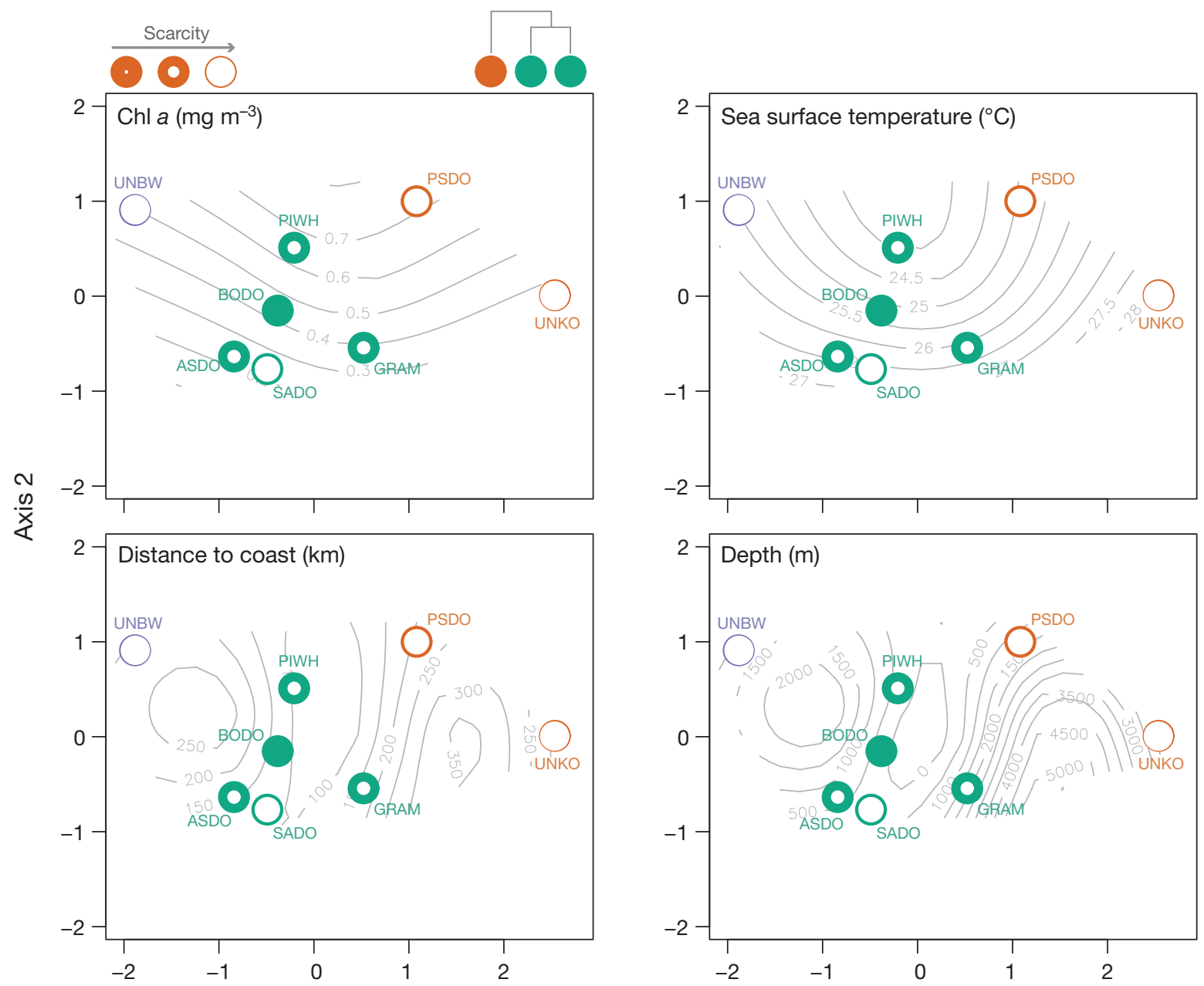

Axis 1

Fig. 5. Plot of $\mathrm{SOH}$ (South of Hatteras) species in ordination space (1st 2 axes) overlaid on a fitted environmental surface (grey contour lines). Species are colored and labeled as in Fig. 4, except for PSDO: pantropical spotted dolphin 

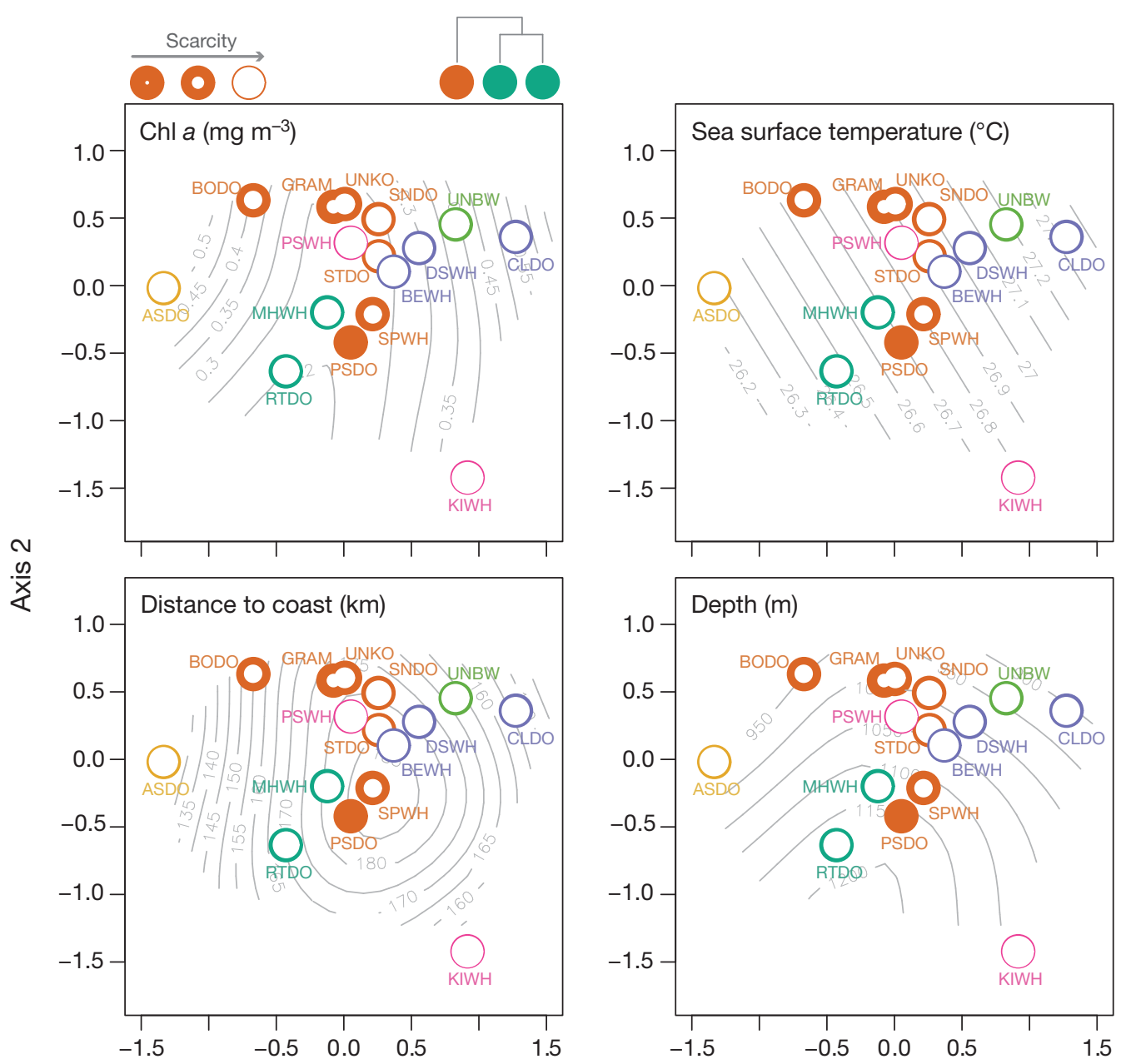

Axis 1

Fig. 6. Plot of GOM (Gulf of Mexico) species in ordination space (1st 2 axes) overlaid on a fitted environmental surface (grey contour lines). Species are colored as in Fig. 4. ASDO: Atlantic spotted dolphin; BEWH: beaked whale (Mesoplodon spp.); BODO: bottlenose dolphin; CLDO: Clymene (short-snouted spinner) dolphin; DSWH: dwarf sperm whale; GRAM: Risso's dolphin; KIWH: killer whale; MHWH: melon-headed whale; PSDO: pantropical spotted dolphin; PSWH: pygmy sperm whale; RTDO: roughtoothed dolphin; SNDO: (long-snouted) spinner dolphin; SPWH: sperm whale; STDO: striped dolphin; UNBW: unidentified beaked whale (Ziphiidae); UNKO: pygmy or dwarf sperm whale

mately midway between the neritic and oceanic groups, with fin whales being seen closest to the center of the neritic group (Fig. 4). In summary, most toothed whales and dolphins were seen farther from shore, in warmer, deeper, less productive waters, while all baleen whales and 3 dolphin species were seen closer to shore, in cooler, shallower, more productive waters (Fig. 4).

\section{South of Hatteras}

$\mathrm{SOH}$ had the least amount of data (14 species seen on 22 sampling hexagons). This region is dominated by a smaller number of Odontocetes (no baleen whales were seen in the $\mathrm{SOH}$ during the summer), many of which are quite spread out in species space (Fig. 5). In the ordination, 3 groups existed although the main group was the most defined (Fig. 5, green circles). This group consisted of pilot whales, bottlenose dolphins, Risso's dolphins, spotted dolphins and common dolphins. Three species were usually seen by themselves: Pantropical spotted dolphin, Kogia spp., and beaked whales (Fig. 5). In general, the main group tended to be in warmer waters that are closer to shore and have lower chl a concentrations (Fig. 5). Pantropical spotted dolphins were seen in cooler waters that are farther from shore and have higher chl a concentrations (Fig. 5). Kogia spp. were seen in the deepest and warmest waters (Fig. 5). 


\section{Gulf of Mexico}

The ordination results from the GOM were less distinct than those from the other 2 areas in terms of differences between groups. Like the $\mathrm{SOH}$ region, the GOM comprised entirely Odontocetes (22 species seen on 53 sampling hexagons). In the GOM, 7 groups were delineated (Fig. 6). The largest group was comprised of bottlenose dolphins, Risso's dolphins, Kogia spp., spinner dolphins, striped dolphins, sperm whales, and Pantropical spotted dolphins (Fig. 6, orange circles). Smaller multiple species groups included: (a) melonheaded whales and rough-toothed dolphins (Fig. 6, dark green circles); and (b) Clymene dolphins, dwarf sperm whales, and beaked whales (Fig. 6, purple circles).

Most of the species were seen in mesotrophic (Kahru \& Mitchell 2000) waters with between 0.2 and $0.3 \mathrm{mg}$ chl $a \mathrm{~m}^{-3}$ (Fig. 6). There was a concave shape to the chlorophyll response, with both Atlantic spotted dolphins and Clymene dolphins being seen in waters with the highest chl a concentrations, the former in cool waters, and the latter in warm waters (Fig. 6). In comparison, the 2 outliers (Atlantic spotted dolphins and killer whales) were seen in similarly productive waters (in terms of chl a concentrations), with killer whales being seen in waters that were $\sim 0.5^{\circ} \mathrm{C}$ warmer, and 10 to $12 \mathrm{~km}$ farther offshore (Fig. 6). Bottlenose dolphins were isolated in species space, and were frequently sighted in neritic waters with higher chl a concentrations (Fig. 6).

\section{Group differences in environment}

In the $\mathrm{NOH}$ region, there were 2 dominant groups (Fig. 4, orange and dark green circles), with significant differences between groups in environmental variables for depth, distance to coast, and sea surface temperature gradient (Table 1). Depth and distance to coast were also significantly correlated with group membership in the $\mathrm{SOH}$ region, along with distance to shelf (Table 1). Depth was significantly correlated with group membership in the GOM, but the correlation was very small (Table 1). There were significant, albeit very small, negative correlations with the probability of an SST front and MLD in NOH (Table 1). These variables were not significant in SOH or GOM (Table 1).

\section{Lumping versus splitting}

Grouping species at higher taxonomic levels caused significant shifts in the larger identified groups (Fig. 7). When we lumped beaked whales at higher taxonomic
Table 1. Mantel correlations between group membership and the 7 environmental variables for each of the 3 regions. Because of the large size of the dataset from the North of Hatteras $(\mathrm{NOH})$ region, we calculated a bootstrapped Mantel $\mathrm{R}$, which is reported along with $95 \%$ CIs when the CI for the $\mathrm{R}$ statistic did not include 0 (i.e. the correlation was significant). SOH: South of Hatteras, SST: sea surface temperature, prob.: probability; MLD: depth of the mixed layer, GOM: Gulf of Mexico, ns: not significant ( $p>0.05)$

\begin{tabular}{|c|c|c|c|}
\hline Region & Variable & Mantel R & $\mathrm{p}$ or $(\mathrm{CI})$ \\
\hline \multirow[t]{7}{*}{ NOH } & Chl a & -0.008 & ns \\
\hline & Depth & 0.286 & $(0.21$ to 0.37$)$ \\
\hline & Distance to coast & 0.288 & (0.21 to 0.36$)$ \\
\hline & Distance to shelf & -0.032 & ns \\
\hline & SST & 0.371 & (0.28 to 0.46$)$ \\
\hline & SST fronts prob. & -0.08 & $(-0.1$ to -0.05$)$ \\
\hline & MLD & -0.09 & $(-0.13$ to -0.04$)$ \\
\hline \multirow[t]{7}{*}{$\mathrm{SOH}$} & $\mathrm{Chl} \mathrm{a}$ & -0.051 & ns \\
\hline & Depth & 0.284 & 0.001 \\
\hline & Distance to coast & 0.208 & 0.0005 \\
\hline & Distance to shelf & 0.332 & 0.0002 \\
\hline & SST & 0.046 & ns \\
\hline & SST fronts prob. & -0.026 & ns \\
\hline & MLD & -0.06 & ns \\
\hline \multirow[t]{7}{*}{ GOM } & Chl a & -0.046 & ns \\
\hline & Depth & 0.083 & 0.001 \\
\hline & Distance to coast & 0.035 & ns \\
\hline & Distance to shelf & 0.027 & ns \\
\hline & SST & -0.011 & ns \\
\hline & SST fronts prob. & -0.073 & ns \\
\hline & MLD & -0.013 & ns \\
\hline
\end{tabular}

levels, they were generically in the oceanic group (Fig. 7); however, when we analyzed the data at the species level, 2 additional groups comprised of Cuvier's and Sowerby's beaked whales emerged (Fig. 4). When beaked whales were lumped across taxonomic levels, the fine scale ecological distinctions were lost (Fig. 8); when identified at the species level, beaked whales separated out into distinct ecological niches (e.g. Sowerby's in cooler water than Cuvier's; Fig. 4). In addition, there were other subtle differences, with the right whales and pilot whales changing their group membership slightly with splitting or lumping of taxonomic groups, although these 2 species were distant from the other group members in both cases (Fig. 7).

\section{DISCUSSION}

\section{North of Hatteras}

The most obvious signal in the ordination is the distinction between the neritic and the oceanic species groups, with the former inhabiting cooler, shallower, 

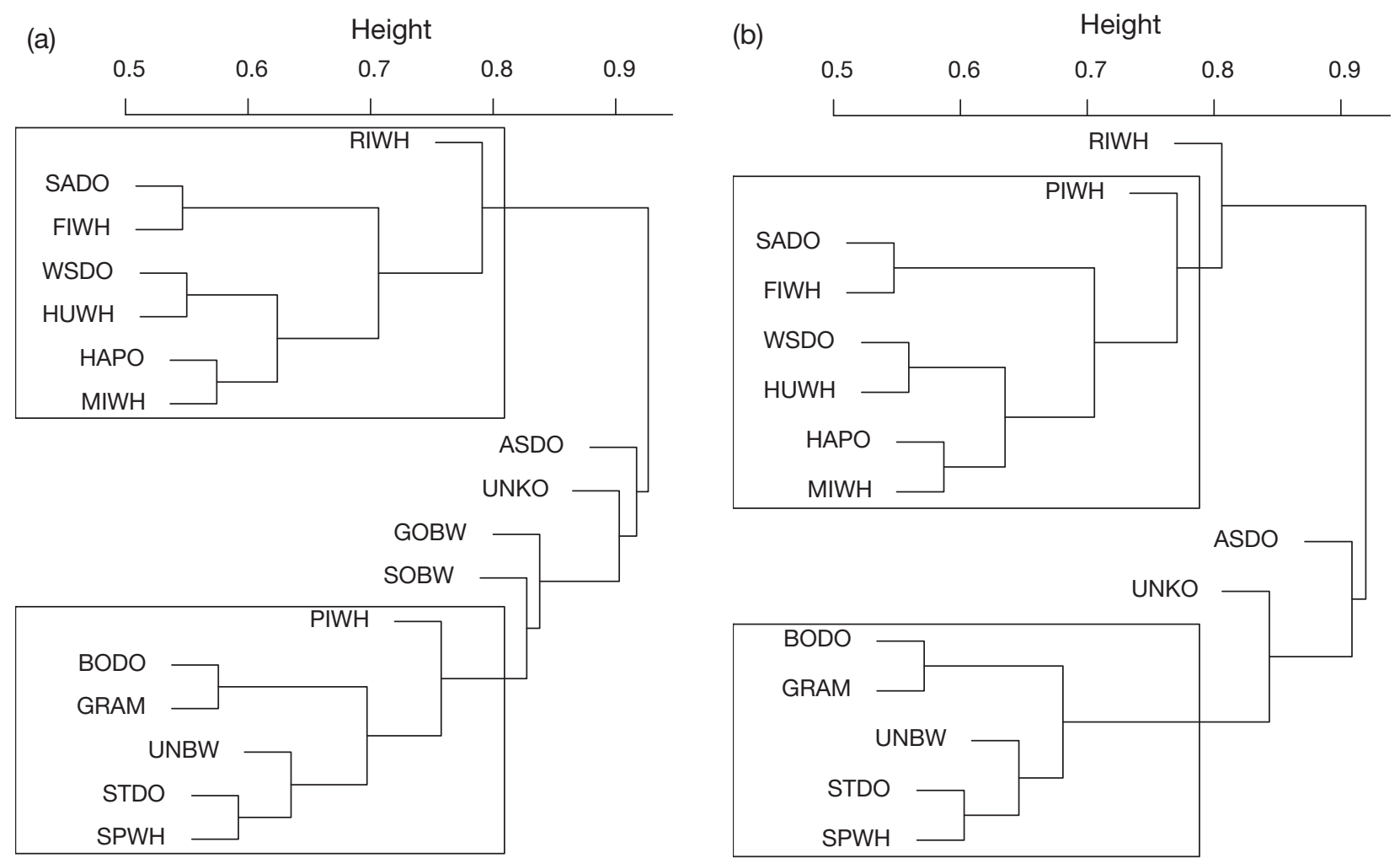

Fig. 7. Dendrogram resulting from hierarchical k-means clustering using a group average linkage for the common species sighted in the North of Hatteras region. (a) Six groups were determined using group contrast Mantel tests (see 'Materials and methods -Classification' for details); rectangles surround groups containing $>1$ species, while e.g. pygmy sperm whales (UNKO) comprised their own group. (b) Five groups resulted from lumping sightings across taxonomic levels, i.e. all beaked whales (GOBW, SOBW, UNBW) are the 'same' species in the ordination. The same is true for pilot whales, i.e. sightings at the species level are the same as sightings at the genus level, which lumps short-finned and long-finned pilot whales. Note especially how lumping the beaked whales moves all sightings into the 'oceanic' group (b), as seen in Fig. 4. Conversely, when we identified beaked whales to the species level, they separated out into distinct ecological communities. Species abbreviations as in Fig. 4

and more productive waters (Fig. 4). These splits are consistent with the trophic guild partitioning outlined by Kenney et al. (1986), i.e. neritic planktivores, oceanic teuthivores (squid eaters), and piscivores. Our results also included harbor porpoises and common dolphins in this neritic group. These visual differences in groups were also quantitatively significant for SST, depth, and distance to coast (Table 1). It is not clear why one of the dynamic variables (SST) was significant, while the 3 others (chl $a$, SST fronts probability, and MLD) were not. Since chl $a$ is at a trophic distance from the prey of many of these species, it is unlikely to be the variable the animals are responding to directly. For SST fronts, it is possible that the climatology does not accurately indicate what animals are responding to, i.e. there could be a scale mismatch between the environmental layer we used and the foraging response. For MLD, it is possible that the spatial resolution of the climatological variable was too large to denote a response, i.e. there was not enough variation within the MLD raster. Lastly, the lack of correlation between differences in group membership and most of the dynamic variables in all regions may be confounded by the level at which we constructed the 'sites.' A $50 \mathrm{~km}$ hexagon may in fact be too coarse to capture the response to dynamic variables that may exhibit finer scale spatial structure.

The composition of the neritic group makes sense. While the larger baleen whales have larger geographic areas than the smaller cetaceans (white-sided dolphins, harbor porpoises, common dolphins), they are known to feed on prey species concentrated in the Gulf of Maine, such as sand lance (Ammodytes spp.) (Kenney \& Winn 1986). Harbor porpoises are a coastal species, and the population analyzed here is not known to leave the Gulf of Maine during the summer months (Read et al. 1993). Here, harbor porpoises were seen in the coolest, shallowest, and most productive waters; this is consistent with both their life history strategy (Read \& Hohn 1995) and their diet, which is primarily comprised of herring and cod (Smith \& Gaskin 1974, Smith \& Read 1992). Although they are planktivores, 


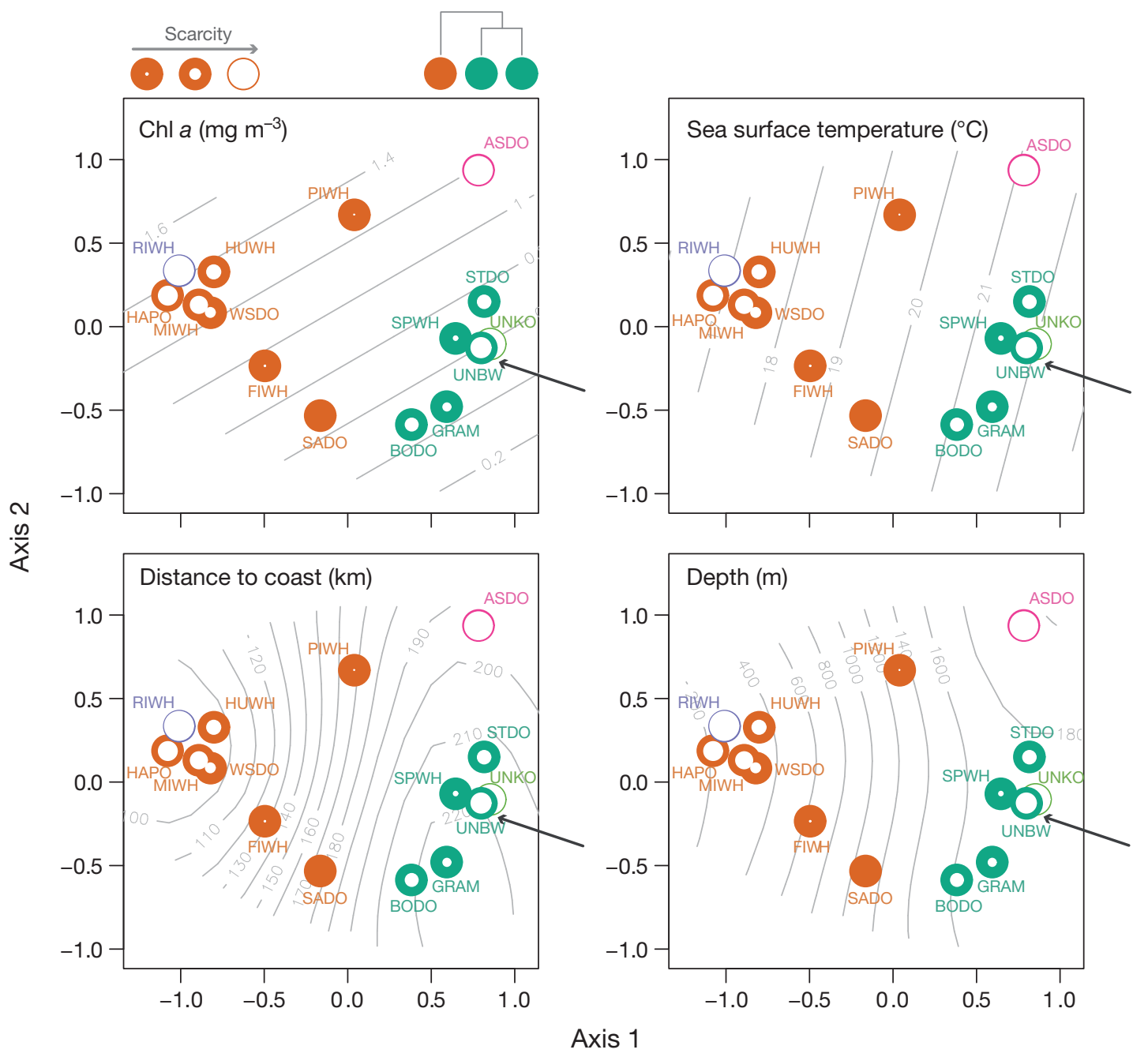

Fig. 8. Same as Fig. 4 except that results are for sightings lumped across taxonomic levels. Grouping follows Fig. 7b. black arrow: new position of beaked whales. Compare to the positions of Cuvier's and Sowerby's beaked whales in Fig. 4

right whales grouped with the other large baleen whales (Fig. 4). Their primary prey, Calanus finmarchicus, is at the base of many fish food chains in the Gulf of Maine (Baumgartner et al. 2007), which helps explain their grouping.

Our oceanic group which is comprised solely of Odontocetes, is also quite similar to the baseline results of Kenney \& Winn (1986) who referred to this group as the teuthivores. Kenney \& Winn's (1986) diet based partition is similar to the grouping results here (Fig. 4). One interesting placement of a species is that for pilot whales, which were only identified to the genus level, and were approximately split between the neritic and oceanic groups (Fig. 4). This placement is likely a compromise between the 2 species in the genus: (1) the long-finned pilot whales which are typically seen in colder, more productive waters, and (2) the short-finned pilot whales which are typically seen in warmer oligotrophic waters (Payne \& Heinemann 1993). While pilot whales grouped out with the oceanic species, their apparent distance from other members in the group might be due to the sightings being recorded at the genus level. As to the placement of bottlenose dolphins, a histogram of the distance to shore data ranged from very close to shore up to $400 \mathrm{~km}$ offshore, indicating that both ecotypes were present in the data (results not shown, but see Fig. 1). Torres et al. (2003) classified all bottlenose dolphins seen farther than $34 \mathrm{~km}$ from the shore into the oceanic ecotype, and the placement here puts bottlenose dolphins well offshore of that distance (Fig. 4). The effect of sighting platform may have an effect on bottlenose dolphins, however, as their position in the ordination is different as a function of platform type (see Supplement 1). Although bottlenose dolphins are considered to be primarily piscivores, dolphins of the oceanic ecotype are 
known to eat squid (Barros \& Odell 1990) as well as fish, which frequently include deep-water fish families (Mead \& Potter 1990). This may help explain why the piscivorous oceanic bottlenose dolphins were grouped with the squid eaters.

Previous work on the distribution of sperm whales and beaked whales (Waring et al. 2001) has noted that while both are shelf edge species (Kenney \& Winn 1986), sperm whales are more widespread than beaked whales and are typically seen close to the edges of warm core rings (Waring et al. 1993, 2001). Waring et al. (2001) found sperm whales in warmer waters than beaked whales; however, their analysis lumped beaked whales across species. Here, we found Sowerby's beaked whales in cooler waters than sperm whales, as expected. However, Cuvier's beaked whales were in fact seen in warmer waters than sperm whales, suggesting fine scale habitat partitioning among these deep diving squid eating species. The distinctions between beaked whales and SST values observed here, i.e. Sowerby's in cooler waters than Cuvier's, are similar to those reported previously (MacLeod 2000, Macleod et al. 2006). While both are shelf associated squid eating species, Sowerby's are smaller, and size differences among beaked whales may lead to prey partitioning (MacLeod \& D'Amico 2006).

\section{South of Hatteras}

One of the biggest differences of $\mathrm{SOH}$ from $\mathrm{NOH}$ and GOM is sample size. Because of the relative scarcity in survey effort (Waring et al. 1997, Mullin \& Fulling 2003), summertime in SOH has notably fewer sightings than that in the other 2 areas. While groups emerged from the data (Fig. 5), the spacing in the group undoubtly reflects the paucity of sightings. Whereas Risso's dolphins and bottlenose dolphins were closely grouped in the other 2 areas (Figs. 4 \& 6), they are farther apart in SOH. Risso's dolphins were seen in cooler, more productive waters. While bottlenose dolphins were the most abundant species in this survey, most bottlenose dolphins migrate north of Cape Hatteras, and hence into the NOH region in summertime (Torres et al. 2005). The small sample size might also explain the lack of significance for the test of group differences as a function of dynamic environmental variables (chl $a, \mathrm{SST}, \mathrm{MLD}$, and SST fronts probability; Table 1).

\section{Gulf of Mexico}

Perhaps the most complex structure in the ordination results was seen in the GOM (Fig. 6), which had the highest number of groups (7), and significant structuring in environmental space (Fig. 6). Depth was a significant patterning variable (Fig. 6, Table 1); however, the correlation between depth and group membership was much smaller in GOM than in $\mathrm{NOH}$ or $\mathrm{SOH}$. This is likely because as compared to the other regions, more sightings in the GOM were over the shelf (Fig. 2). Nevertheless, this result matched previous work on distributions in the GOM (Baumgartner 1997, Davis et al. 1998, Baumgartner et al. 2001, Mullin \& Fulling 2004). These papers have produced an understanding of species specific habitat depth partitioning in this region: shelf species (Atlantic spotted dolphins, bottlenose dolphins), upper slope species (Risso's dolphins, short-finned pilot whales), lower slope species (Kogia spp., roughtoothed dolphins, spinner dolphins, sperm whales), and oceanic species (striped dolphins, melon-headed whales, Pantropical spotted dolphins, Clymene dolphins, beaked whales) (Davis et al. 1998, 2002, Baumgartner et al. 2001). Where this overlap in species space existed, species tended to separate on subsequent environmental variables, e.g. Risso's and Kogia spp. overlapped in depth but differed in slope and zooplankton biomass, with Risso's being seen in high slope environments, and Kogia being typically seen in areas of higher zooplankton biomass (Baumgartner 1997, Baumgartner et al. 2001). Similarly, Davis et al. (1998) noted that oceanic stenellids and sperm whales were seen over similar depths, but that physiology restricts the stenellids to upper portions of the water column (Williams et al. 1993), while sperm whales are deeper divers (Watkins et al. 1993).

The depth partitioning observed here is consistent with previous work (Davis et al. 1998, Baumgartner et al. 2001, Davis et al. 2002) with a few exceptions. Rough-toothed dolphins were seen in deeper waters than other lower slope species (Fig. 6), while Clymene dolphins and beaked whales were seen in shallower waters than other oceanic species (Fig. 6). These exceptions may be due to several of these studies examining a smaller spatial range, i.e. western continental slope (Davis et al. 1998), northern oceanic GOM (Davis et al. 2002), or the continental shelf (Fulling et al. 2003), whereas the data presented here cover a slightly larger range (Fig. 2). Differences could also be due to seasonality in the community and/or in the survey effort, leading to certain species being seen more frequently in the summer (Mullin \& Fulling 2004) and some being seen more frequently in spring (Jefferson \& Schiro 1997).

Previous authors have highlighted biologically important areas in the GOM, including the area off the Mississippi River delta, and the shelf area west of southern Florida (Davis et al. 1998, Baumgartner et 
al. 2001, Fulling et al. 2003). The patterns that influence the environment in these places are notably different, with productivity in the Mississippi River delta area being influenced by river discharge, and the Loop Current playing a much larger role in the SW Florida shelf (Davis et al. 1998, Baumgartner et al. 2001, Fulling et al. 2003). Thus, while productivity could be similar in both places, species response to each of these influences might vary considerably by area. Many factors contribute to the pattern of species observed in ordination space, including time, space, observation effort, environmental characteristics, and the cryptic nature of certain species. All of these constraints must be taken into account when relating our results with previous studies. A fuller understanding of patterns in these communities requires a larger dataset collected across all seasons and over multiple years.

\section{Overlap}

There are more subtle patterns observed within the macro-scale results. For example, in $\mathrm{NOH}$, a clear distinction exists between the major groups (Fig. 4). However, even within these groups, there is structure worth examining. Several of the species seen appeared to cluster quite closely in ordination space. In the neritic group seen in $\mathrm{NOH}$, the apparent overlap is slightly misleading, as the ordination results in 3 dimensions indicated separation along the 3 axes (represented with color in the groups in Fig. 4). Right whales were in the most productive waters (Fig. 4a), and this is likely because their primary prey (Calanus spp.) is much more closely linked to primary productivity than prey items at higher trophic levels. Right whales, humpback whales, harbor porpoises, minke whales, and white-sided dolphins were all seen in the most productive waters, while the other members of the group (fin whales, common dolphins) were seen in warmer, less productive waters (Fig. 4). In addition to diet preferences, morphological and physiological adaptations may explain some of this separation (Bowen et al. 2002). For example, the baleen of minke whales is shorter than those of other baleen whales, making the species better adapted to a diet that is high in fish content (Bowen et al. 2002).

Animals in the GOM appeared to be partitioning along a depth gradient, yet any apparent overlap likely does not extend through the water column since diving physiology limits certain species to certain parts of the water column (Williams et al. 1993, Davis et al. 1998). The importance of the 3D habitat stresses how a complete picture of the community structure needs further information on prey, and diving physiology.

\section{Temporal dynamics}

Clearly, time plays an important role in pelagic realms. Palacios (2003) showed how individual species and the community groups they form shifted their spatial distribution over time. He speculated on the role of large-scale oceanographic events like El Niño, which significantly change oceanographic regimes; notably, he postulated an increased competition for space during an El Niño event as favorable conditions for upwelling species are reduced. Similarly, all 3 regions discussed herein are subject to the influence of major oceanographic features, i.e. the Western Boundary Current (Lohrenz \& Verity 2006, Townsend et al. 2006). In the GOM, the Loop Current is a dominant hydrographic feature. The penetration of the current into the GOM changes with time, and has been speculated to impact the position of individual species, which in turn could change community structure. In addition, there is a seasonal signal to the discharge from the Mississippi River. Both of these events have been postulated to affect the environment and cetacean responses (Davis et al. 2002, Lohrenz \& Verity 2006). In the SOH, the Gulf Stream can occupy one of 2 dominant positional modes (Lohrenz \& Verity 2006). The interaction between the relative position of the Gulf Stream and the topography of the region can have large effects on cross-shelf nutrient transport, as well as on-shelf primary productivity (Lohrenz \& Verity 2006), which in turn must surely affect top predators. Although we lack quantitative information on these links, the dominant oceanography of the region is clearly important.

Similarly, in the NOH region, the interaction between the northward extent of the Gulf Stream and the relative strength of the North Atlantic Oscillation can influence the oceanography of the entire region (Townsend et al. 2006). For example, the Gulf of Maine (located entirely within the $\mathrm{NOH}$ region) plankton and zooplankton communities have shifted in response to the freshening of the upstream oceanic inputs (Pershing et al. 2004, Greene \& Pershing 2007). The long-term effect of these signals is unclear, but the calving response in planktivorous whales has already been linked to these events (Greene \& Pershing 2007). Should the prey base change, the community structure within the $\mathrm{NOH}$ might also change. While we have ignored annual variation in this analysis, a fruitful investigation would be to conduct ordination analyses at yearly time steps, and then compare the relative position of species within ordination space and the relative change in community composition through time. Such an analysis would deepen our understanding of how the regional oceanography and its variability impact cetacean species and communities. 
Lastly, we know that several of the baleen whales seen in $\mathrm{NOH}$ migrate into and out of this region within the year. For example, pregnant female right whales migrate between $\mathrm{NOH}$ and $\mathrm{SOH}$ and the migratory corridor between these regions is critically important, yet understudied (Schick et al. 2009). While we ignored within-year variability, comparing seasonal species climatologies would provide insight into how these communities typically change within a year.

\section{Management implications}

The research presented here spans 3 major biogeographic zones (Spalding et al. 2007), and includes data from oceanic systems where even less is known about species distributions. Two of the 3 geographic areas analyzed here have benefited from major research efforts for cetaceans: CETAP for the Northeast (Cetacean \& Turtle Assessment Program 1982), and GulfCet I and II for the Gulf of Mexico (Jefferson 1995, Davis \& Fargion 1996, Baumgartner 1997, Jefferson \& Schiro 1997, Davis et al. 1998, 2000, Würsig et al. 2000). No similar effort exists for the area south of Cape Hatteras (Waring et al. 1997, Mullin \& Fulling 2003). Accordingly, there is a stark need for more data collection in space (e.g. in the $\mathrm{SOH}$ region) and in time (e.g. throughout all seasons within years and across years).

For survey planners, the groups uncovered herein can provide a reference for the types of species that are sighted together as well as those that are frequently sighted alone; e.g. if you are seeing Risso's dolphins in the GOM, you should also expect to see Kogia spp. (Fig. 6). In addition to the collection of data on cetaceans, it is imperative to consider data on the different trophic levels of these ecosystems. The oceanography of these regions is reasonably well understood (Lohrenz \& Verity 2006, Townsend et al. 2006), but the link from the oceanography up to the response of top predators is less well understood. Studies across trophic levels would complement the existing understanding of the physical dynamics.

A key need in the management of cetaceans is a better understanding of the beaked whale group (MacLeod 2000, MacLeod \& D'Amico 2006, Macleod \& Mitchell 2006, Macleod et al. 2006). These species are difficult to observe at sea, regardless of the survey platform, and are even harder to identify to the species level (Figs. 4 \& 8). Macleod et al. (2006) have already noted how taxonomic lumping can have profound effects on our knowledge of their distribution, which in turn could have effects on how we define, understand, and monitor key areas (Macleod \& Mitchell 2006). Previous investigators have called for additional research in these key areas: species identification; surveys in understudied areas; and study of the factors that determine species ranges (Macleod et al. 2006). We underscore these research needs, specifically as they relate to the ecology and conservation of beaked whales, which are poorly understood and are vulnerable to anthropogenic noise.

Lastly, more research into specific environmental variables and the response of individual species to these environmental variables is needed from an ecological standpoint. In addition to increased understanding of species-environment relationships, we stress the need to understand how animals respond to acute and chronic disturbances. The eastern seaboard of the USA is heavily developed, and includes many large seaports. Understanding how shipping related disturbances differentially impact species discussed herein would aid management and conservation efforts. This is an especially acute need for the cryptic species noted above.

Acknowledgements. We thank 4 anonymous reviewers whose comments and suggestions considerably strengthened this manuscript. We also thank J. Oksanen for help with and minor tweaks to his already excellent vegan package in $R_{;} D$. Dunn for help with the bathymetry layer in the overview maps; and R. Brady, Director of the Visualization Technology Group at Duke University, for help with the graphics. This work was partly supported by SERDP/DoD grant W912HQ04-C-0011 to A.J.R. and P.N.H. as well as a James B. Duke Fellowship and a Harvey L. Smith Dissertation Year Fellowship to R.S.S.

\section{LITERATURE CITED}

Angel M (1979) Zoogeography of the Atlantic Ocean. In: Van der Spoel S, Pierrot-Bults AC (eds) Zoogeography and diversity of plankton. Edward Arnold, London, p 168-190

Austin MP (1985) Continuum concept, ordination methods, and niche theory. Annu Rev Ecol Syst 16:39-61

Ballance LT, Pitman RL, Reilly SB (1997) Seabird community structure along a productivity gradient: importance of competition and energetic constraint. Ecology 78: 1502-1518

Barros NB, Odell DK (1990) Food habits of bottlenose dolphins in the southeastern United States. In: Leatherwood $\mathrm{S}$, Reeves RR (eds) The bottlenose dolphin. Academic Press, San Diego, CA, p 309-328

Baumgartner MF (1997) The distribution of Risso's dolphin (Grampus griseus) with respect to the physiography of the Northern Gulf of Mexico. Mar Mamm Sci 13:614-638

Baumgartner M, Mayo C, Kenney R (2007) Chapter 5. Enormous carnivores, microscopic food, and a restaurant that's hard to find. In: Kraus SD, Rolland RM (eds) The urban whale: North Atlantic right whales at the crossroads. Harvard University Press, Cambridge, MA, p 138-173

Baumgartner M, Mullin K, May L, Leming T (2001) Cetacean habitats in the northern Gulf of Mexico. Fish Bull 99: 219-239

> Baumgartner MF, Cole TVN, Campbell RG, Teegarden GJ, Durbin EG (2003) Associations between North Atlantic 
right whales and their prey, Calanus finmarchicus, over diel and tidal time scales. Mar Ecol Prog Ser 264:155-166 Best BD, Halpin PN, Fujioka E, Read AJ, Qian SS, Hazen LJ, Schick RS (2007) Geospatial web services within a scientific workflow: predicting marine mammal habitats in a dynamic environment. Ecol Inform 2:210-223

Bowen WD, Read AJ, Estes JA (2002) Feeding ecology. In: Rus Hoelzel A (ed) Marine mammal biology: an evolutionary approach. Blackwell Science, Malden, MA, p 217-256

Cetacean \& Turtle Assessment Program (1982) Final report to the Bureau of Land Management. University of Rhode Island, Kingston, RI

Clarke K (1993) Non-parametric multivariate analyses of changes in community structure. Aust J Ecol 18:117-143

Clarke KR, Ainsworth M (1993) A method of linking multivariate community structure to environmental variables. Mar Ecol Prog Ser 92:205-219

Connell JH (1961) The influence of interspecific competition and other factors on the distribution of the barnacle Chthamalus stellatus. Ecology 42:710-723

Davis, RW, Evans WE, Würsig B (2000) Cetaceans, sea turtles and seabirds in the northern Gulf of Mexico: distribution, abundance and habitat associations, Vol II. Technical report. Texas A\&M University, Galveston and the NMFS. US Dep Interior, Geological Survey, Biological Resources Division, USGS/BED/CR-1999-0006 and Minerals Management Service, Gulf of Mexico OCS Region, New Orleans, LA

Davis RW, Fargion GS (1996) Distribution and abundance of cetaceans in the north-central and western Gulf of Mexico: final report, Vol II. Technical report. Texas Institute of Oceanography and NMFS. US Dep Interior, Minerals Management Service, Gulf of Mexico OCS Region, New Orleans, LA

Davis R, Fargion G, May N, Leming T and others (1998) Physical habitat of cetaceans along the continental slope in the northcentral and western Gulf of Mexico. Mar Mamm Sci 14:490-507

> Davis RW, Ortega-Ortiz JG, Ribic CA, Evans WE and others (2002) Cetacean habitat in the northern oceanic Gulf of Mexico. Deep-Sea Res I 49:121-142

De'ath G, Fabricious K (2000) Classification and regression trees: a powerful yet simple technique for ecological data analysis. Ecology 81:3178-3192

Ekman S (1953) Zoogeography of the sea. Sidgwick \& Jackson, London

Fiedler PC, Reilly SB (1994) Interannual variability of dolphin habitats in the eastern tropical Pacific. II. Effects on abundances estimated from tuna vessel sightings, 1975-1990. Fish Bull 92:451-463

Field J, Clarke K, Warwick R (1982) A practical strategy for analysing multispecies distribution patterns. Mar Ecol Prog Ser 8:37-52

Fulling GL, Mullin KD, Hubard CW (2003) Abundance and distribution of cetaceans in outer continental shelf waters of the U.S. Gulf of Mexico. Fish Bull 101:923-932

> Greene CH, Pershing AJ (2007) Climate drives sea change. Science 315:1084-1085

Halpin PN, Read AJ, Best BD, Hyrenbach KD and others (2006) OBIS-SEAMAP: developing a biogeographic research data commons for the ecological studies of marine mammals, seabirds, and sea turtles. Mar Ecol Prog Ser 316:239-256

Halpin PN, Read AJ, Fujioka E, Best DD and others (2009) OBIS-SEAMAP: the world data center for marine mammal, sea bird, and sea turtle distributions. Oceanography 22:104-115
Hamazaki T (2002) Spatiotemporal prediction models of cetacean habitats in the mid-western North Atlantic ocean (from Cape Hatteras, North Carolina, U.S.A. to Nova Scotia, Canada) Mar Mamm Sci 18:920-939

Hutchinson GE (1957) Concluding remarks. Cold Spring Harb Symp Quant Biol 22:415-427

Hyrenbach KD, Veit RR, Weimerskirch H, Metzl N, Hunt GL (2007) Community structure across a large-scale ocean productivity gradient: marine bird assemblages of the southern Indian Ocean. Deep-Sea Res I 54:1129-1145

Jefferson TA (1995) Distribution, abundance and some aspects of the biology of cetaceans in the offshore Gulf of Mexico. Texas A\&M University, College Station, TX

Jefferson T, Schiro A (1997) Distribution of cetaceans in the offshore Gulf of Mexico. Mammal Rev 27:27-50

> Kahru M, Mitchell BG (2000) Influence of the 1997-98 El Niño on the surface chlorophyll in the California Current. Geophys Res Lett 27:2937-2940

Kenney RD, Winn HE (1986) Cetacean high-use habitats of the northeast United States continental shelf. Fish Bull 84: 345-357

Kenney R, Hyman M, Owen R, Scott G, Winn H (1986) Estimation of prey densities required by western North Atlantic right whales. Mar Mamm Sci 2:1-13

Kraus SD, Rolland R (2007) The urban whale: North Atlantic right whales at the crossroads. Harvard University Press, Cambridge, MA

Legendre P, Legendre L (1998) Numerical ecology. Elsevier, Amsterdam

Lohrenz SE, Verity PG (2006) Regional oceanography: southeastern United States and Gulf of Mexico $(2, \mathrm{~W})$. In: Robinson AR, Brink KH (eds) The sea, Vol 14A. The global coastal ocean: interdisciplinary regional studies and syntheses. Harvard University Press, Cambridge, MA, p 169-224

MacLeod C (2000) Distribution of beaked whales of the genus Mesoplodon in the North Atlantic. Mammal Rev 30:1-8

MacLeod CD, D'Amico A (2006) A review of beaked whale behaviour and ecology in relation to assessing and mitigating impacts of anthropogenic noise. J Cetacean Res Manag 7:211-221

Macleod C, Mitchell G (2006) Key areas for beaked whales worldwide. J Cetacean Res Manag 7:309-322

Macleod C, Perrin W, Pitman R, Barlow J and others (2006) Known and inferred distributions of beaked whale species (Cetacea: Ziphiidae). J Cetacean Res Manag 7:271-286

> McGowan JA, Walker PW (1979) Structure in the copepod community of the North Pacific central gyre. Ecol Monogr 49:195-226

McGowan JA, Walker PW (1985) Dominance and diversity maintenance in an oceanic ecosystem. Ecol Monogr 55: $103-118$

Mead JG, Potter CW (1990) Natural history of bottlenose dolphins along the central Atlantic coast of the United States. In: Leatherwood S, Reeves RR (eds) The bottlenose dolphin. Academic Press, San Diego, CA, p 165-195

Mullin K, Fulling G (2003) Abundance and distribution of cetaceans in the southern US Atlantic Ocean during summer 1998. Fish Bull 101:603-613

Mullin KD, Fulling GL (2004) Abundance of cetaceans in the oceanic northern Gulf of Mexico, 1996-2001. Mar Mamm Sci 20:787-807

Newman MJH, Paredes GA, Sala E, Jackson JBC (2006) Structure of Caribbean coral reef communities across a large gradient of fish biomass. Ecol Lett 9:1216-1227

Oksanen J, Guillaume Blanchet F, Kindt R, Legendre P and others (2010) vegan: community ecology package. Available at http://vegan.r-forge.r-project.org/ 
Paine RT (1966) Food web complexity and species diversity. Am Nat 100:65-75

Palacios DM (2003) Oceanographic conditions around the Galapagos Archipelago and their influence on cetacean community structure. Oregon State University, Corvallis, OR

Payne PM, Heinemann DW (1993) The distribution of pilot whales (Globicephala sp.) in shelf/shelf edge and slope waters of the northeastern United States, 1978-1988. In: Donovan GP, Lockyer CH, Martin AR (eds) Reports of the International Whaling Commission, special issue 14: biology of northern hemisphere pilot whales. Int Whaling Comm, Cambridge, UK, p 51-68

Pershing AJ, Greene CH, Planque B, Fromentin JM (2004) The influence of climate variability on North Atlantic zooplankton populations. In: Stenseth NC, Ottersen G, Hurrell J, Belgrano A (eds) Ecological effects of climatic variations in the North Atlantic. Oxford University Press, Oxford, p 59-69

R Development Core Team (2010) R: a language and environment for statistical computing. R Foundation for Statistical Computing, Vienna

Read AJ, Hohn AA (1995) Life in the fast lane: the life history of harbor porpoises from the Gulf of Maine. Mar Mamm Sci 11:423-440

Read AJ, Kraus SD, Bisack KD, Palka D (1993) Harbor porpoises and gill nets in the Gulf of Maine. Conserv Biol 7: 189-193

Reilly SB, Fiedler PC (1994) Interannual variability of dolphin habitats in the eastern tropical Pacific. I. Research vessel surveys, 1986-1990. Fish Bull 92:434-450

Roberts JJ, Best BD, Dunn DC, Treml EA, Halpin PN (2010) Marine geospatial ecology tools: an integrated framework for ecological geoprocessing with ArcGIS, Python, R, MATLAB, and C++. Environ Model Softw 25:1197-1207

Schick RS, Halpin PN, Read AJ, Slay CK and others (2009) Striking the right balance in right whale conservation. Can J Fish Aquat Sci 66:1399-1403

Smith GJ, Gaskin DE (1974) The diet of harbor porpoises (Phocoena phocoena (L.)) in coastal waters of eastern Canada, with special reference to the Bay of Fundy. Can J Zool 52:777-782

Smith R, Read A (1992) Consumption of euphausiids by harbour porpoise (Phocoena phocoena) calves in the Bay of Fundy. Can J Zool 70:1629-1632

Spalding, MD, Fox HE, Allen GR, Davidson N and others (2007) Marine ecoregions of the world: a bioregionalization of coastal and shelf areas. Bioscience 57:573-583

Steele JH (1991) Marine functional diversity. Bioscience 41: $470-474$

Editorial responsibility: Matthias Seaman, Oldendorf/Luhe, Germany
Stommel H (1963) Varieties of oceanographic experience. Science 139:572-576

Torres LG, Mclellan WA, Meagher E, Pabst DA (2005) Seasonal distribution and relative abundance of bottlenose dolphins, Tursiops truncatus, along the US mid-Atlantic coast. J Cetacean Res Manag 7:153-161

Torres LG, Rosel PE, D'Agrosa C, Read AJ (2003) Improving management of overlapping bottlenose dolphin ecotypes through spatial analysis and genetics. Mar Mamm Sci 19: 502-514

Townsend DW, Thomas AC, Mayer LM, Thomas MA, Quinlan JA (2006) Oceanography of the northwest Atlantic continental shelf $(1, \mathrm{~W})$. In: Robinson AR, Brink KH (eds) The sea, Vol 14A. The global coastal ocean: interdisciplinary regional studies and syntheses. Harvard University Press, Cambridge, MA, p 119-168

Urban D, Goslee S, Pierce K, Lookingbill T (2002) Extending community ecology to landscapes. Ecoscience 9:200-212

Venrick EL (1982) Phytoplankton in an oligotrophic ocean: observations and questions. Ecol Monogr 52:129-154

- Venrick EL (1990) Phytoplankton in an oligotrophic ocean: species structure and interannual variability. Ecology 71: $1547-1563$

Waring GT, Fairfield CP, Ruhsam CM, Sano M (1993) Sperm whales associated with Gulf Stream features off the northeastern USA shelf. Fish Oceanogr 2:101-105

> Waring GT, Hamazaki T, Sheehan D, Wood G, Baker S (2001) Characterization of beaked whale (Ziphiidae) and sperm whale (Physeter macrocephalus) summer habitat in shelfedge and deeper waters off the Northeast US. Mar Mamm Sci 17:703-717

Waring GT, Palka D, Mullin K, Hain J, Hansen L, Bisack K (1997) US Atlantic and Gulf of Mexico marine mammal stock assessments 1996. US Dep Commerce. NOAA Tech Memo, NMFS NE 114

Watkins WA, Daher MA, Fristrup KM, Howald TJ, Di Sciara GN (1993) Sperm whales tagged with transponders and tracked underwater by sonar. Mar Mamm Sci 9:55-67

Williams T, Friedl W, Haun J, Chun N (1993) Balancing power and speed in bottlenose dolphins (Tursiops truncatus). In: Boyd IL (ed) Marine mammals: advances in behavioural and population biology. Proc Symp Zool Soc Lond 66:383-394

Woehler EJ, Raymond B, Watts DJ (2003) Decadal-scale seabird assemblages in Prydz Bay, East Antarctica. Mar Ecol Prog Ser 251:299-310

Würsig B, Jefferson TA, Schmidly DJ (2000) The marine mammals of the Gulf of Mexico. Texas A\&M University Press, College Station, TX

Submitted: June 8, 2010; Accepted: April 28, 2011

Proofs received from author(s): July 19, 2011 